\title{
EUROCAT: 25 years of European surveillance of congenital anomalies
}

\author{
H Dolk
}

Arch Dis Child Fetal Neonatal Ed 2005;90:F355-F358. doi: 10.1136/adc.2004.062810

The surveillance of congenital anomalies serves two main purposes: to facilitate the identification of teratogenic (malformation causing) exposures and to assess the impact of primary prevention and prenatal screening policy and practice at a population level. EUROCAT, the European network of population based registers for the epidemiological surveillance of congenital anomalies, now covers 1.2 million births per year, a quarter of births in Europe. The added value of European collaboration is particularly great for congenital anomalies, coming from the opportunity to pool data, to compare data between regions and countries, to give a common response to European public health questions, and to share expertise and resources, including computing tools. EUROCAT provides essential epidemiological information on congenital anomalies in Europe, facilitates the early warning of teratogenic exposures, evaluates the effectiveness of primary prevention, assesses the impact of developments in prenatal screening, acts as an information and resource centre regarding clusters, provides a ready collaborative network and infrastructure for research, and acts as a catalyst for the setting up of registries throughout Europe.

\section{Correspondence to: Professor Dolk, EUROCAT Project Leader, Epidemiology and Health Services Research, University of Ulster at Jordanstown, Shore Rd, Newtownabbey BT37 OQB, UK; h.dolk@ulster. ac.uk'}

Accepted 17 May 2005
$\mathrm{T}$ he surveillance of congenital anomalies serves two main purposes: to facilitate the identification of teratogenic (malformation causing) exposures and to assess the impact of primary prevention and prenatal screening policy and practice at a population level.

EUROCAT, the European network of registers for the epidemiologic surveillance of congenital anomalies (box 1), has a 25 year history (box 2). It now covers 1.2 million births per year, a quarter of births in Europe (table 1), and includes almost all population based registers of congenital anomaly in Europe as its members. Maintaining high quality data usually requires a limit to the total size of the population to be covered by a register, thus the preference in larger nations for regional rather than national registries, networked nationally and at a European level by EUROCAT. The added value of European collaboration is particularly great for congenital anomalies, coming from the opportunity to pool data, to compare data between regions and countries, to give a common response to European public health questions, and to share expertise and resources, including computing tools. Funding for network coordination currently comes from the European Commission's Directorate General for Health and Safety, under its Public Health Programme, as a component of the European information system for rare diseases. EUROCAT is also a WHO Collaborating Centre for the Epidemiologic Surveillance of Congenital Anomalies.

Prevalence data on a wide range of congenital anomalies in all member regions is made freely available on the EUROCAT website, ${ }^{1}$ detailing the number of cases of more than 80 types of congenital anomaly reported among live births, stillbirths, and terminations of pregnancy after prenatal diagnosis, and the prevalence as a proportion of all births. The seemingly effortless appearance of these figures belies the years of work that have gone into establishing registers across Europe, agreeing a common dataset and coding scheme, ${ }^{2}$ and identifying, and where possible addressing, variation in diagnostic or organisational factors that may contribute to "artefactual" geographic and temporal differences in prevalence. ${ }^{3}$ The total reported prevalence of congenital anomalies-including live births, stillbirths, and terminations of pregnancy after prenatal diagnosis-has increased during the last 25 years, ${ }^{13}$ mainly because the age at diagnosis of many internal anomalies, such as certain cardiac and urinary system anomalies, has been brought forward to the prenatal or early postnatal period, thus entering the main information sources for registries, and also because prenatal diagnosis followed by termination of pregnancy brings into the information system cases of congenital anomaly that would otherwise have gone undiagnosed or unreported among spontaneous abortions. Two congenital anomalies show a clear real increase in total prevalence since 1980: Down syndrome, because of the increasing average maternal age across Europe; gastroschisis, because of unknown environmental factors. ${ }^{3}{ }^{4}$ The situation regarding hypospadias, of interest as a potential outcome of endocrine disrupting exposures, is unclear, although EUROCAT data do not indicate an increase in prevalence since 1980. ${ }^{5}$ Geographic variation within Europe is evident for a number of anomalies, including oral $\operatorname{clefts}^{367}$ and omphalocele, ${ }^{8}$ whereas variation is reducing for neural tube defects. ${ }^{3}{ }^{10}$

Population based registries are a particularly powerful tool for evaluation of health services because they represent the experience of the entire community, not the outcomes of specialist units, which may serve only a selected group of 


\section{Box 1: Objectives of EUROCAT}

- To provide essential epidemiological information on congenital anomalies in Europe

- To facilitate the early warning of teratogenic exposures

- To evaluate the effectiveness of primary prevention

- To assess the impact of developments in prenatal screening

- To act as an information and resource centre regarding clusters or exposures or risk factors of concern

- To provide a ready collaborative network and infrastructure for research related to the causes and prevention of congenital anomalies and the treatment and care of affected children

- To act as a catalyst for the setting up of registries throughout Europe collecting comparable, standardised data

women or children, or which may have atypical human or financial resources. EUROCAT's 25 year history has spanned the expansion of prenatal screening and diagnosis. For some anomalies, prenatal diagnosis may improve prognosis because of the opportunity to plan surgery or other intervention. For severe anomalies, the most common result is termination of pregnancy, depending on the legal situation and gestational age limit in each country. ${ }^{11}$ The prevalence of terminations 1998-2002 ranged from 0 to $1.1 \%$ of births in the different regional populations. ${ }^{1}$ Comparisons of the proportion of cases prenatally diagnosed, the average gestational age at diagnosis, diagnostic methods used, and the proportion of cases resulting in termination of pregnancy have shown enormous variation between and within countries. $^{4}{ }^{12-14}$ Such variation may result from cultural differences underlying policy or individual uptake, differing interpretations of the scientific evidence in the design and implementation of screening, or differences in resources and systems in place to effect change in the health services. The livebirth prevalence of Down syndrome now varies fourfold across Europe ${ }^{3}$ from 6 to 25 per 10000 births in individual regions, this variation bearing more relationship to the situation regarding prenatal diagnosis and termination of pregnancy than the maternal age structure of each population.

The main disappointment in congenital anomaly prevention over the last 15 years has been the very small impact of periconceptional folic acid supplementation on the prevalence of neural tube defects. ${ }^{9}{ }^{10}$ Despite more than a decade since randomised controlled trial results in 1991 confirmed the preventive potential, only a shallow decline in total prevalence occurred in Britain and Ireland by 2001 (a continuation of a much stronger decline in the 1980s and earlier), and no overall decline in prevalence was observed in the rest of Europe. ${ }^{9}{ }^{10}$ This concurred with numerous surveys showing that a minority of women take supplements starting preconceptionally. The existence and coordination of population based registries is vital for the monitoring of future policy developments. Surveillance in North America has been able to show the impact of folic acid fortification of flour in reducing the prevalence of neural tube defects. ${ }^{15}$ Moreover from 2005 births, socioeconomic variables included in the EUROCAT dataset will allow examination of the impact of different policies on socioeconomic inequalities in neural tube defect prevalence, as surveys have shown that supplementation uptake is higher among women of higher social

\section{Box 2: History of EUROCAT}

The development of the concept of EUROCAT took place in the 1970s (Weatherall JACW. The beginnings of EUROCAT. Louvain-la-Neuve, Belgium: Cabay, 1985), bringing together moves in the European Commission to circumvent the lack of provision for health in the Treaty of Rome, the aim of the Committee on Medical and Public Health Research of the EEC to prepare a concerted action in the field of epidemiology, and the interests of key epidemiologists in congenital malformations and their causes. Still very much in the wake of the thalidomide tragedy, it was felt that congenital malformations would provide a good model or feasibility study for European epidemiological monitoring, which would fulfil the goal of "something which brings the doctors in, brings the public in, has a great public health importance, is not controversial, and has great (scientific) opportunities for the future" ${ }^{\prime \prime}$. Additional considerations were the amenability of the problem to prevention and concrete action, educational impact, and the need for promotion of norms and standards at international level. EUROCAT has always existed on precariously short term funding contracts. From 1979 until 1991, funding came from the Directorate General for Research, and thereafter from the Directorate General for Health and Consumer Protection as a provider of surveillance information. Funding has always been limited to coordination, with national governments or other bodies responsible for local funding. In most countries, regional and/or national funding for congenital anomaly registries has been as precarious as that of the coordinating EUROCAT centre. So 25 years later there is still work to be done to give congenital anomaly surveillance a stable framework in Europe, with enough funding to fully exploit the potential that 25 years of joint work has built up for surveillance and research.

class, and inequalities are therefore likely to widen under current policies.

There is ongoing discussion as to the role of congenital anomaly surveillance in preventing another thalidomide-type tragedy. Statistical monitoring may pick up a change in

Table 1 Coverage of the European population by EUROCAT registries

\begin{tabular}{llll}
\hline Country & Annual births & $\begin{array}{l}\text { No of EUROCAT } \\
\text { registries }\end{array}$ & $\begin{array}{l}\text { \% of country } \\
\text { covered }\end{array}$ \\
\hline Austria & 75800 & 1 & 14.2 \\
Belgium & 116900 & 2 & 26.1 \\
Bulgaria & 68200 & 1 & 15.0 \\
Croatia & 47500 & 1 & 12.0 \\
Denmark & 65300 & 1 & 8.7 \\
Finland & 56100 & 1 & 100.0 \\
France & 772500 & 4 & 20.6 \\
Germany & 743500 & 2 & 2.9 \\
Hungary & 98100 & 1 & 100.0 \\
Ireland & 56100 & 3 & 57.8 \\
Italy & 545000 & 5 & 31.2 \\
Malta & 3900 & 1 & 100.0 \\
Netherlands & 200200 & 1 & 10.2 \\
Norway & 57000 & 1 & 100.0 \\
Poland & 363200 & 1 & 54.3 \\
Portugal & 114800 & 1 & 15.9 \\
Spain & 407400 & 4 & 34.3 \\
Sweden & 91800 & 1 & 100.0 \\
Switzerland & 73600 & 1 & 9.9 \\
United Kingdom & 669000 & 8 & 35.2 \\
\hline
\end{tabular}

Non-covered EU countries: Cyprus, Czech republic, Estonia, Greece, Latvia, Lithuania, Luxembourg, Slovakia and Slovenia 
frequency, the surveillance system can provide a rapid population based response to the observations of the "alert clinician", or it can be used to assess how well the use of known teratogenic drugs is avoided in pregnancy. ${ }^{16}$ We are fortunate not to have experienced any further event of the scale of thalidomide, but it is likely that drugs remain on the market with less dramatic population effects, where the drug is less widely used and the teratogenic risks are lower, or restricted to smaller genetically or otherwise susceptible subpopulations. This is an area on the borderline between surveillance and research where we need to graft on to ongoing surveillance a variety of methods, including casecontrol approaches with accurate data on women's medication history during pregnancy, linkages between congenital anomaly registries and clinical databases of women with specific diseases (epilepsy, diabetes) or having undergone specific treatments (assisted conception), and linkages between registers and prescription databases. Only a subset of EUROCAT registries are resourced to do this ${ }^{17}{ }^{18}$ or can overcome the confidentiality restrictions placed on such research.

The potential for environmental pollution to cause congenital anomalies is the issue most likely to hit the headlines. On the one hand, we are faced with the problem of congenital anomaly clusters identified in the community. Is this a random cluster, an unusual aggregation of cases but one that is inevitably thrown up by random processes, or a cluster due to a localised environmental cause? EUROCAT's Cluster Advisory Service ${ }^{19}$ collects together experience as to how to assess such clusters, how to investigate them, and how to communicate with concerned communities. Surveillance data can be used to assess whether such clustering is occurring near "similar" sources of pollution to that suspected of causing the cluster, although the definition of "similar" is often problematic. On the other hand, we can address environmental concerns more directly, whether acute incidents such as Chernobyl ${ }^{20}{ }^{21}$ or chronic pollution from sources such as landfill sites. ${ }^{20} 22$ We are still a long way from achieving an adequate scientific assessment of risks related to environmental pollution. Progress in this area is a particular challenge for a health surveillance network because of the need for interdisciplinary collaboration, in particular with regard to the measurement of exposure, which is so much less readily defined than drug exposure. One of the challenges for risk communication with patients and the public is to discuss the degree of, reasons for, and implications of current scientific uncertainty.

The involvement of registries in research is essential to maintain their dynamism and quality. Every two years, a European Symposium on the Prevention of Congenital Anomalies is hosted by a member registry to provide an opportunity to present and discuss local and collaborative research. ${ }^{17}$ EUROCAT also values links with European researchers and clinicians to exploit the unique central database of over 300000 case records, or to use the collaborative infrastructure of population based registries for additional data collection-for example, on occupational exposure. $^{23}$

Each registry follows national practice in terms of their supervision by ethics and steering committee and representation on those committees. Registers in some countries are currently in a difficult position because of national interpretations of the European directive regarding patient consent. Although a reasonable requirement in theory, experience shows that, although refusals are very rare, obtaining parental consent for registration is logistically difficult and requires resources much greater than those usually made available. Moreover, the duty not to register without consent seems to have eclipsed the duty to ask consent and give parents an opportunity to contribute to continuing surveillance and research to improve the health of children.

\section{ACKNOWLEDGEMENTS}

EUROCAT is funded by the European Commission Directorate General Health Public Health Programme. This paper is written on behalf of all EUROCAT Registry Leaders (Lenore Abramsky, North Thames, UK; Marie-Claude Addor, Vaud, Switzerland; Ingeborg Barisic, Zagreb, Croatia; Sebastiano Bianca, Sicily, Italy; Fabrizio Bianchi, Tuscany, Italy; Patricia Boyd, Oxford, UK; Rosa Caballin, El Valles, Spain; Elisa Calzolari, Emilia Romagna, Italy; Catherine de Vigan, Paris, France; Hermien de Walle, North Netherlands; Elizabeth Draper, Trent, UK; Maria Feijoo, South Portugal; Christine Francannet, Auvergne, France; Ester Garne, Odense, Denmark; Miriam Gatt, Malta; Yves Gillerot, Hainaut-Namur, Belgium; Martin Haeusler, Styria, Austria; Maria Howard, Merseyside, UK; Lorentz Irgens, Norway; Anna Latos-Bielenska, Poland; David Lillis, Galway, Ireland; Marie-Luisa Martinez-Frias, Madrid, Spain; Bob McDonnell, Dublin, Ireland; Carmen MosqueraTenreiro, Asturias, Spain; Vera Nelen, Antwerp, Belgium; Birgitta Ollars, Sweden; Mary O'Mahony, Cork \& Kerry, Ireland; Isabel Portillo, Basque Country, Spain; Annette Queisser-Luft, Mainz, Germany; Annukka Ritvanen, Finland; Elisabeth Robert, Central East France; Joaquin Salvador, Barcelona, Spain; Janos Sandor, Hungary; Gioacchino Scarano, Campania, Italy; Volker Steinbicker, Saxony-Anhalt, Germany; Claude Stoll, Strasbourg, France; David Stone, Glasgow, UK; Romano Tenconi, North East Italy; Radka Tincheva, Sofia, Bulgaria; David Tucker, Wales, UK; Martin Ward Platt, Northern Region, UK; Diana Wellesley, Wessex, UK), all EUROCAT Central Registry staff (Araceli Busby, Ester Garne, Elaine Hand, Maria Loane, Barbara Norton), and Central Registry collaborators (Alan Kelly, Ireland; Lolkje de Jong van den Berg, Netherlands).

Competing interests: none declared

\section{REFERENCES}

A full list of EUROCAT publications can be found on www. eurocat. ulster.ac.uk/pubdata

1 http://www.eurocat.ulster.ac.uk/pubdata/tables.html (accessed Jan 2005).

2 EUROCAT Guide 1.2: instructions for the registration of congenital anomalies, University of Ulster, 2002. www.eurocat.ulster.ac.uk/pubdata.

3 EUROCAT Report 8: surveillance of congenital anomalies in Europe 19801999. University of Ulster, 2002

4 Dolk H, Loane M, Garne E, et al. Trends and geographic inequalities in the prevalence of Down Syndrome in Europe 1980-1999. Revues Epidemiol Sante Publique 2005; in press.

5 Dolk H, Vrijheid, Scott JES, et al. Towards the effective surveillance of hypospadias. Environ Health Perspect 2004;112:398-402.

6 EUROCAT Working Group. EUROCAT Special Report: EUROCAT and orofacial clefts: the epidemiology of orofacial clefts in 30 European regions. EUROCAT Central Registry, University of Ulster, University of Ferrara, Italy, and the CNR Institute of Clinical Physiology, Pisa, Italy, 2002, www.eurocat.ulster.ac.uk/pubdata.

7 Calzolari E, Bianchi F, Rubini $M$, et al. Epidemiology of cleft palate in Europe: implications for genetic research strategy. Cleft Palate Craniofac J 2004;41:244-9.

8 Calzolari E, Bianchi F, Dolk H, et al. Omphalocele and gastroschisis in Europe: a survey of 3 million births 1980-90. Am J Med Genet 1995;58:187-94.

9 EUROCAT Folic Acid Working Group. EUROCAT special report: prevention of neural tube defects by periconceptional folic acid supplementation in Europe. EUROCAT Central Registry, University of Ulster, 2003. www.eurocat.ulster.ac.uk/pubdata.

10 Busby A, Abramsky L, Dolk H, et al. Preventing neural tube defects in Europe: population-based study. BMJ 2005;330:574-5.

11 EUROCAT Working Group. EUROCAT Special Report: prenatal screening policies in Europe. EUROCAT Central Registry, University of Ulster, 2005. www.eurocat.ulster.ac.uk/pubdata.

12 Garne E, Loane M, Dolk H, et al. Prenatal diagnosis of congenital malformations in Europe. Ultrasound Obstet Gynecol 2005;25:6-11.

13 Garne E, Loane M, de Vigan C, et al. Prenatal diagnostic procedures in pregnancies with congenital malformations in 14 regions of Europe. Prenat Diagn 2004;24:908-12.

14 Clementi M, Stoll C. The EUROSCAN study. Ultrasound Obstet Gynecol 2001;18:297-300.

15 De Wals P, Rusen ID, Lee NS, et al. Trend in prevalence of neural tube defects in Quebec. Birth Defects Res Part A Clin Mol Teratol 2003;67:919-23.

16 Yang $Q$, Khoury M, James $L M$, ef al. The return of thalidomide: are birth defects surveillance systems ready? Am J Med Genet 1997;73:251-8.

17 EUROCAT. 7th European Symposium on the Prevention of Congenital Aomalies, 30 May 2003, Heidelberg, Germany. Conference programme. Reprod Toxicol 2004;18:135-56. 
18 Meijer WM, Cornel MC, Dolk H, et al. The potential of the European network of congenital anomaly registers (EUROCAT) for drug safety surveillance. Pharmacoepidemiol Drug Saf 2005; in press.

19 www.eurocat.ulster.ac.uk/clusteradvservice. $h$ tml.

20 EUROCAT Working Group. EUROCAT Special Report: a review of environmental risk factors for congenital anomalies. EUROCAT Central Registry, University of Ulster. 2004. www.eurocat.ulster.ac.uk/pubdata.
21 Dolk H, Nichols R. Evaluation of the impact of Chernobyl on the prevalence of congenital anomalies in 16 regions of Europe. Int J Epidemiol 1999;28:941-8. 22 Dolk H, Vriiheid M, Armstrong B, et al. Risk of congenital anomalies near hazardous waste landfill sites in Europe: the EUROHAZCON study. Lancet 1998;352:423-7.

23 Cordier S, Bergeret A, Goujard J, et al. Congenital malformations and maternal occupational exposure to glycol ethers. Epidemiology 1997;8:355-63.

\section{bmjupdates+}

bmjupdates+ is a unique and free alerting service, designed to keep you up to date with the medical literature that is truly important to your practice.

bmjupdates+ will alert you to important new research and will provide you with the best new evidence concerning important advances in health care, tailored to your medical interests and time demands.

\section{Where does the information come from?}

bmjupdates+ applies an expert critical appraisal filter to over 100 top medical journals A panel of over 2000 physicians find the few 'must read' studies for each area of clinical interest

Sign up to receive your tailored email alerts, searching access and more...

www.bmjupdates.com 